\title{
PRÁTICAS AVALIATIVAS PARA A APRENDIZAGEM DE PROFESSORES NUMA UNIDADE MUNICIPAL DE EDUCAÇÃO INFANTIL \\ https://dx.doi.org/10.5902/2318133868004
}

\author{
Marciel Barcelos ${ }^{1}$ \\ Aline Oliveira Vieira² \\ Wagner dos Santos ${ }^{3}$
}

\section{Resumo}

Neste texto apresentam-se resultados de pesquisa pela qual objetivou-se compreender os sentidos atribuídos por docentes de uma instituição de educação infantil sobre as práticas avaliativas para aprendizagem mobilizadas no cotidiano escolar. A pesquisa teve caráter qualitativo e utilizou-se como método o estudo de caso etnográfico. Os participantes da pesquisa foram 24 professores que atuam numa instituição de educação infantil na cidade de Vila Velha/ES. Como documentos utilizou-se narrativas, diário de campo e registros imagéticos. A análise dos dados sinalizou para o compartilhamento de uma concepção avaliativa formativa reguladora centralizada no docente, de maneira que o sentido produzido por meio das práticas avaliativas está associado ao caráter informativo daquilo que se passa no cotidiano escolar.

Palavras-chave: avaliação educacional; educação infantil; escolarização.

\section{EVALUATIVE PRACTICES FOR TEACHING LEARNING IN A CHILDREN'S EDUCATION MUNICIPAL UNIT}

\section{Abstract}

This paper presents the results of a research that aimed to understand the meanings attributed by the faculty of an early childhood education institution about the evaluative practices for learning mobilized in school quotidian. The research was qualitative and the method used was the ethnographic case study. The research participants were 24 teachers who work in an early childhood education institution in the city of Vila Velha/ES. Narratives, field diary and imagery records were adopted as documents. Data analysis signaled the sharing of a regulatory formative evaluative conception centered on the faculty, in order that the meaning produced through the evaluative practices is associated with the informative character of what happens in daily school life.

Key-words: educational assessment; child education; schooling.

\footnotetext{
${ }^{1}$ Universidade Federal do Tocantins, Brasil. E-mail: marcielbarcelos@gmail.com.

2 Prefeitura Municipal de Serra/ES, Brasil. E-mail: ninnamanquinhos@gmail.com.

3 Universidade Federal do Espírito Santo, Brasil. E-mail: wagnercefd@gmail.com.

68004 , p. $1-18$ 


\section{Introdução}

N este texto apresenta-se resultados de pesquisa pela qual objetivou-se compreender quais os sentidos atribuídos, pelos docentes de uma instituição de educação infantil localizada no município de Vila Velha/ES, sobre a avaliação para aprendizagem ${ }^{4}$ (Harlen; James, 1997) mobilizadas ao longo de um ano letivo.

Analisar a avaliação no contexto da educação infantil ganha relevância pela emergência de estudos nessa etapa da educação básica. Nos últimos quinze anos pesquisas do tipo revisão sistemática (Santos et al., 2018; Glap; Brandelisse; Rosso, 2014; López-Pastor et al., 2013; Mota; Mamede-Neves, 2021), ao tomarem como fontes artigos em periódicos, sinalizam um aumento de investigações da temática na educação básica, contudo, são congruentes na afirmativa de que ainda são poucos os trabalhos que pesquisam práticas avaliativas na educação infantil.

Alavarse, Chappaz e Freitas (2021) destacam que a avaliação é peça chave no processo de formação de um professor, mas que encontra-se esvaziada nos cursos de formação de professores. Tal ação impacta na forma como os docentes interpretam as práticas realizadas pelas crianças no processo de escolarização, fazendo com que ações carregadas de sentidos e saberes se perca nas intricadas relações cotidianas, especialmente na educação infantil.

Nesse sentido, chamamos atenção para os estudos apontam a lacuna na formação de professores sobre seus saberes avaliativos e se propõe a apresentar possibilidades de como fazer as práticas avaliativas no cotidiano escolar (Santos, 2005; Santos et al., 2014; Santos et al., 2015, Santos et al., 2018, Vieira, 2018; Costa, 2017). Essa ação permite ampliar as possibilidades de interpretação daquilo que a criança faz com o que aprende (Lano, 2019) a partir de uma base teórica de cunho investigativa (Esteban, 2001), fazendo com que o docente perceba que o processo avaliativo retroalimenta as práticas, potencializando as ações no cotidiano escolar.

Contudo, os estudos sinalizados assumem como o contexto do ensino fundamental anos iniciais e finais e, para essa pesquisa, focalizamos no processo avaliativo na educação infantil. Assim, foi preciso entender que não há uma infância ou uma criança ideal nesse contexto, mas infâncias e crianças que apresentam diferentes especificidades e praticam os cotidianos à sua maneira, fazendo com que as ações realizadas pelos docentes considerem essa especificidade (Barcelos; Santos; Ferreira Neto, 2015; 2017; 2021).

\footnotetext{
${ }^{4}$ Para Harlen e James (1997) a avaliação para aprendizagem não está preocupada em gerar nota ou juízos de valor que podem ser transformados em notas, mas sim com a qualidade e melhoria das aprendizagens. Nesse sentido, trata-se de uma ação que objetiva subsidiar docentes e discentes sobre seu percurso formativo e o estágio de desenvolvimento de suas aprendizagens, podendo, assim, reordenar a trajetória
} educativa. 


\section{Método}

O método utilizado foi o estudo de caso etnográfico. Ele nos permitiu produzir fontes sobre um fenômeno específico que ocorre em determinado contexto, em nosso caso os sentidos atribuídos pelos professores ao ato de avaliar na educação infantil de uma Unidade Municipal de Educação Infantil, localizada na cidade de Vila Velha/ES. Sarmento (2003) destaca que

os 'estudos de caso' de escolas são, portanto, um formato metodológico que deve a sua divulgação, antes de mais, ao facto de perspectivarem holisticamente as unidades organizacionais, e, no caso dos estudos de base etnográfica, de acrescentarem ao conhecimento de estruturas, regras, interacções e processos de acção, as dimensões existenciais, simbólicas e culturais que se Ihes associam. (p. 3)

Ao assumirmos esse método, mergulhamos no cotidiano escolar analisando as práticas ${ }^{5}$ (Certeau, 1994) daqueles que compõem o cotidiano, produzindo fontes a partir de suas ações e interações naquele contexto, observando e analisando os atravessamentos, aproximações e distanciamentos que ocorrem no processo de ensinoaprendizagem na educação infantil.

Das 38 instituições de educação infantil do município selecionamos a Umei JSM ${ }^{6}$. Participaram da pesquisa 24 professores do turno matutino e vespertino e a coordenadora do turno matutino. No quadro que segue discriminamos o tipo de vínculo do docente com a escola, a experiência profissional, a titulação e a área de formação.

Quadro 1 -

Professores lotados na Umei em 2017.

\begin{tabular}{|c|c|c|c|c|}
\hline Identificação & Tipo de vínculo & $\begin{array}{c}\text { Experiência na } \\
\text { educação infantil }\end{array}$ & Maior titulação & $\begin{array}{c}\text { Área de } \\
\text { formação }\end{array}$ \\
\hline P1 & Efetivo & 14 anos & Lato-sensu & Pedagogia \\
\hline P2 & Efetivo & 6 anos & Lato-sensu & Pedagogia \\
\hline P3 & Efetivo & 12 anos & Lato-sensu & Pedagogia \\
\hline P4 & Efetivo & 15 anos & Especialista & Pedagogia \\
\hline P5 & Efetivo & 2 anos & Lato-sensu & Educação Física \\
\hline P6 & Efetivo & 9 anos & Especialista & Educação Física \\
\hline P7 & Efetivo & 12 anos & Especialista & Pedagogia \\
\hline P8 & Efetivo & 23 anos & Lato-sensu & Pedagogia \\
\hline P9 & Efetivo & 14 anos & Lato-sensu & Pedagogia \\
\hline P10 & Efetivo & 4 anos & Especialista & Pedagogia \\
\hline P11 & Efetivo & 17 anos & Especialista & Pedagogia \\
\hline P12 & Efetivo & 11 anos & Lato-sensu & Pedagogia \\
\hline P13 & Efetivo & 7 anos & Lato-sensu & Pedagogia \\
\hline P14 & Extensão de & 16 anos & Lato-sensu & Pedagogia \\
\hline & carga horária & & & \\
\hline
\end{tabular}

5 Para Certeau (1994), prática são todas as ações dos sujeitos no cotidiano, uma palavra, um movimento, um olhar ou uma conversa casual, tudo aquilo que o praticante faz no cotidiano é entendido como prática, pois revela sua racionalidade e intencionalidade de agir em um determinado contexto.

6 Destacamos que a escola possui 25 professores lotados, contudo, 24 optaram por participar da pesquisa. Nesse sentido, excluímos o P18 do quadro 1.

7 Os professores em extensão de carga horária são profissionais efetivos com jornada de 25 horas no município que optam por estender sua carga horária, a depender das possibilidades na Rede. Isso não se
Regae: Rev. Gest. Aval. Educ.
Santa Maria
v. 11
n. 20
e68004, p. 1-18
2022 


\begin{tabular}{|c|c|c|c|c|}
\hline P15 & Efetivo & 5 anos & Lato-sensu & Pedagogia \\
\hline P16 & Efetivo & 6 anos & Graduação & $\begin{array}{c}\text { Pedagogia e } \\
\text { Artes }\end{array}$ \\
\hline P17 & $\begin{array}{c}\text { Extensão de } \\
\text { carga horária }\end{array}$ & 1 ano & Lato-sensu & Pedagogia \\
\hline P19 & $\begin{array}{c}\text { Efetivo } \\
\text { Designação } \\
\text { temporária }\end{array}$ & 13 anos & Especialista & Pedagogia \\
\hline P21 & Efetivo & 4 anos & Especialista & Pedagogia \\
\hline P22 & Efetivo & 5 anos & Lato-sensu & Educação Física \\
\hline P23 & Efetivo & 12 anos & Lato-sensu & Pedagogia \\
\hline P24 & Efetivo & 5 anos & Graduação & Pedagogia \\
\hline C1 & Efetivo & 5 anos & Lato-sensu & Pedagogia \\
\hline
\end{tabular}

Fonte: autores.

Acompanhamos os professores lotados na referida instituição de ensino às quintasfeiras, de 7 às $11 \mathrm{~h}$, do primeiro dia letivo, em 6 de fevereiro, até 14 de julho, no ano de 2017. Utilizamos um questionário semiestruturado como instrumento de coleta de dados. Continha 17 questões organizadas nos seguintes blocos: formação acadêmica e experiência profissional: cinco questões; sentimento quanto ao ato de avaliar: cinco questões; como avalio e quando avalio: três questões; por que e para que avalio: três questões; e a última pergunta, aberta, questionava os professores sobre o que era avaliar.

Com o instrumento de coleta de dados buscou-se identificar suas experiências formativas e trajetória profissional, bem como a forma como mobilizam a avaliação na educação infantil. Outro instrumento utilizado foi o diário de campo. Nele registrávamos as narrativas produzidas nos encontros de planejamento ${ }^{9}$ durante as aulas e nos diferentes espaços praticados (Certeau, 1994) pelo professor no cotidiano escolar. Assim, ampliamos o entendimento sobre as fontes produzidas pelo questionário, oportunizando 0 movimento de olhar as fontes por diferentes ângulos (Sarmento, 2003).

É importante destacar que compartilhamos do entendimento de Certeau (1994) sobre a transformação de lugares em espaços. Para o autor o lugar é constituído de uma lógica própria, organizada a partir das estratégias ${ }^{10}$ produzidas pelos praticantes do cotidiano. À medida em que esse lugar é ocupado e praticado por aqueles que constituem o cotidiano, as táticas ${ }^{11}$ reconfiguram esse lugar transformando-o em espaço.

Após a tabulação dos dados, organizamos as narrativas do diário de campo. De acordo com Certeau (1994), levamos em conta que o fazer do pesquisador caminha na perspectiva de observar a maneira como a fala foi organizada, nos entrecruzamentos

configura como um novo contrato de trabalho, mas, sim, como um adicional de carga horária e de remuneração.

8 Profissional contratado por meio de processo seletivo, que possui vínculo empregatício não estatutário com duração de 12 meses, com possibilidade de prorrogação por mais 12 meses.

9 Destacamos que, por vezes, os encontros de planejamento ocorriam com mais de um professor, possibilitando ampliar as possibilidades de interpretação e de análise sobre um determinado assunto.

10 Para Certeau (1994), as estratégias são intencionalidades construídas no cotidiano, elas se apresentam nos lugares, nas regras, nas ações que buscam determinar uma forma de ser e de agir daqueles que compartilham um determinado contexto.

${ }^{11}$ Para Certeau (1994), as táticas são as maneiras que os praticantes do cotidiano utilizam para subverter as lógicas que instituem um lugar. Eles fazem usos dos consumos realizados para ressignificar suas práticas de acordo com suas vontades e demandas dos lugares.

Regae: Rev. Gest. Aval. Educ. $\quad$ Santa Maria 11 v. 11 n. 20

e68004, p. 1-18

2022 
entre o dito no questionário e o narrado pelo docente no dia a dia da escola; o jogo ético e estético com a linguagem: nos movimentos de autoria das práticas de experiências narradas, destacando os elementos textuais visíveis e silenciados no relato; a atividade da memória: continuidades e rupturas na maneira de dizer do docente em relacionar o vivido com outros momentos de experiências de vida.

Essa operação de organização das fontes nos permitiu elaborar duas categorias de análise: a primeira, intitulada 'da formação inicial às concepções avaliativas', em que discutimos os atravessamentos e as maneiras de fazer e compreender a avaliação na educação infantil. E a segunda - 'as experiências compartilhadas de práticas avaliativas' na qual analisamos as práticas mobilizadas pelos docentes, assim como sua articulação com as concepções avaliativas. Na última categoria abrimos um subtópico para abordar o uso do desenho como prática avaliativa, uma vez que percebemos suas potencialidades naquele contexto educacional.

\section{Da formação inicial aos motivos de se avaliar na educação infantil}

Uma de nossas preocupações na Umei JSM foi compreender os motivos que levam os professores a avaliar. Assim, foi preciso identificar, nas suas respostas e narrativas, como essas ações tencionavam o seu fazer avaliativo. Isso posto, sistematizamos os dados em tabelas e, posteriormente, cruzamos esses resultados com as narrativas registradas em diário de campo.

No gráfico 1, evidencia-se os lugares em que os professores lotados na instituição se aproximaram do debate sobre avaliação para aprendizagem na sua formação inicial ou trajetória profissional.

Gráfico 1 -

Sobre as orientações recebidas acerca de avaliação para aprendizagem na educação infantil ${ }^{12}$.

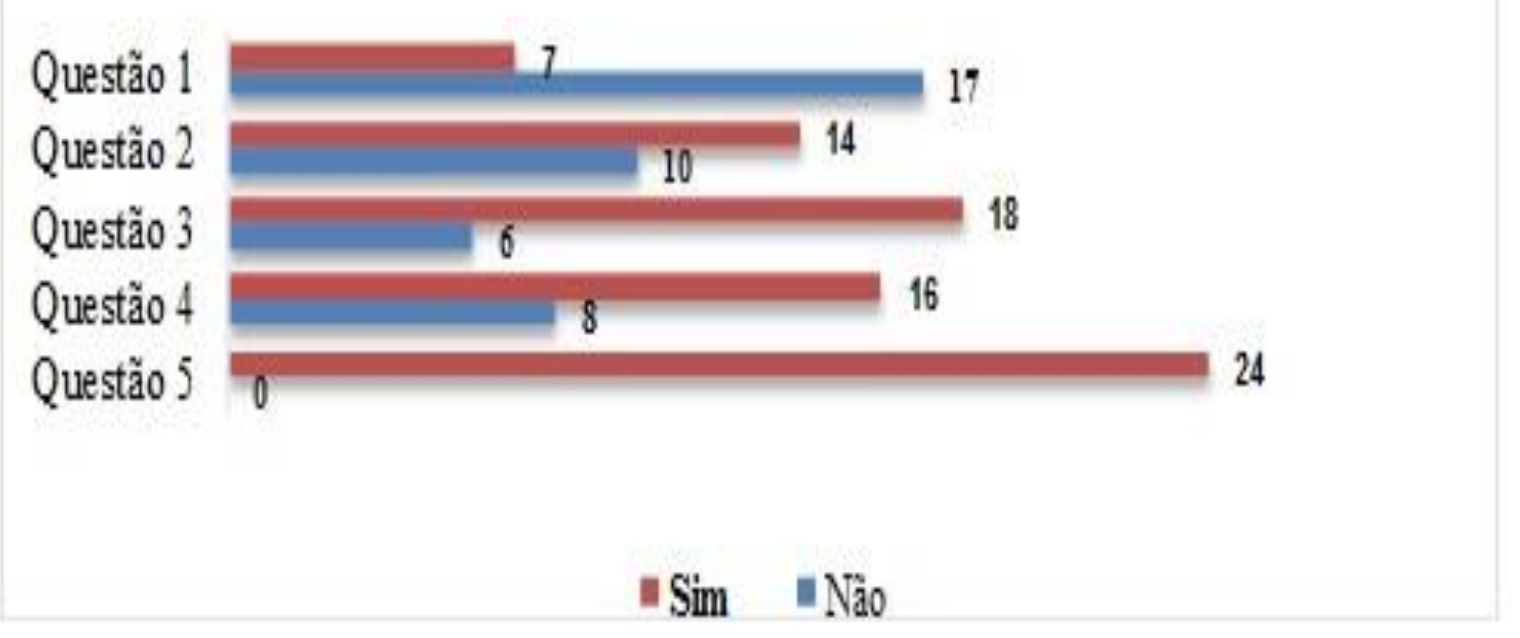

Fonte: autores.

12 Questão 1: Na minha formação inicial; Questão 2: Em formações continuadas ofertadas pelas Secretarias Municipais e/ou Estadual de Educação; Questão 3:Em Congressos/Seminários ofertados por universidades e/ou outros órgãos; Questão 4: Na escola em que atuo, em conversas com o pedagogo nos planejamentos e reuniões coletivas com os outros professores da escola; Questão 5: Por iniciativa própria. 
Os dados evidenciam a importância da formação continuada para os professores em relação às práticas avaliativas na educação infantil. A ausência de uma disciplina que discuta a especificidade da avaliação, relacionando-a com a primeira etapa da educação básica, também é evidenciada pelos docentes.

Fuzii (2010), ao analisar cursos de formação de professores em Pedagogia, sinalizou que o debate sobre avaliação na educação infantil tem sido diluído nas disciplinas que compõem o curso. De acordo com a autora esse movimento faz com que os docentes busquem, em outras fontes, subsídios para compreender o processo avaliativo nesse contexto. Esse cenário identificado pelo autor também é afirmado por pesquisas que discutem as percepções dos discentes em formação inicial em relação aos conhecimentos apropriados sobre avaliação na formação inicial e sua projeção para atuação docente na área da educação física (Goc-Karp; Woods, 2008; Santos; Maximiano, 2013).

No movimento de produção de fontes registramos a narrativa de P5 sobre sua formação inicial: "Na graduação? Na graduação contato com avaliação só nos estágios e na disciplina de didática" (Narrativa, P5, 2017). Já P10 faz uma análise das experiências formativas, destacando onde teve contato com a avaliação e a sua preocupação pelo modo como era articulada ao trabalho realizado na escola: "Eu só fui ver sobre avaliação na disciplina de didática, nos estágios tinha que pôr nos planos de aula, mas raramente a gente era cobrado sobre isso, na educação infantil então, nem se tocava no assunto." (Narrativa, P10, 2017)

Chamamos atenção para a secundarização da discussão da avaliação na formação dos professores, contribuindo para o aumento do interesse e a necessidade de promoção de cursos de formação continuada e de pesquisa em uma ação autoformativa. Essa ação autoformativa, resultado do próprio movimento do cotidiano escolar (Lano, 2019), é produzida como espaço privilegiado de compartilhamentos das experiências formativas na educação infantil. $\mathrm{Na}$ análise de nossas fontes identificamos duas formas distintas em que essa ação ocorre: a primeira institucional e a segunda colaborativa.

A coordenadora da instituição (C1) forneceu indícios de como ocorre a forma institucional a partir dos encontros de formação continuada promovidos pelo município de Vila Velha/ES:

"Eu, pessoalmente, nos últimos dois anos, fui em três formações só sobre avaliação na educação infantil. Primeira era para falar como poderíamos orientar. A segunda para a gente dar a devolutiva para a formadora. E a terceira foi para falar sobre instrumentos avaliativos. Teve até um curso no E-proinfo13 para os professores, eu fiz, teve um módulo só sobre avaliação na educação infantil. Eu acho que é algo que a prefeitura está investindo bastante." (Narrativa, C1, 2017)

O investimento em formação continuada sinaliza à necessidade de debate sobre o tema no contexto da educação infantil, garantido não só a dimensão do cuidar, mas também do educar e de compreender as apropriações das crianças daquilo que se ensina e mais, daquilo que se faz com o que se aprende (Santos, 2005; Vieira, 2018; Lano, 2019).

${ }^{13}$ Ambiente virtual de colaboração para a formação do Ministério da Educação.

\begin{tabular}{|l|l|l|l|l|l|}
\hline Regae: Rev. Gest. Aval. Educ. & Santa Maria & v. 11 & n. 20 & e68004, p. 1-18 & 2022 \\
\hline
\end{tabular} 
A narrativa de $\mathrm{C} 1$ traz pistas para entendermos como o debate em torno da avaliação se apresenta na rede municipal de ensino de Vila Velha/ES, iniciando o debate com aqueles que gerenciam pedagogicamente as instituições de ensino. Esse movimento foi percebido nos registros de campo, nos quais há uma preocupação da coordenadora em municiar os docentes da instituição com aquilo que foi apropriado nas formações.

No segundo movimento, de caraterística colaborativa, P20 e P8, que têm mais de 20 anos de experiência na educação infantil, destacam que

"a gente busca compensar essa 'ausência'[de conhecimento sobre avaliação] com pesquisa, a gente olha na internet, conversa com outro colega para entender melhor o que é avaliar, sabe, eu mesmo olho o monte de coisa, copio dos meus colegas e aí eu vou construindo a minha forma de avaliar, observando e ouvindo, principalmente, ouvindo." (Narrativa, P20, 2017)

"Eu já fui muito em congresso, é muito importante, mas o que é mais importante pra mim, atualmente, né, porque isso pode mudar amanhã, o amanhã só a Deus pertence, né, é as conversas que eu tenho com minhas amigas e também a pedagoga me ajudam muito a melhorar meu trabalho." (Narrativa, P8, 2017)

Charlot (2000) evidencia que aprendemos na relação com o outro e na própria compreensão daquilo que fazemos, a partir da análise do outro. Dessa maneira, aprender a avaliar na Umei JSM é um movimento coletivo, mas também estratégico e tático (Certeau, 1994) na medida em que ressignifica aquilo que aprenderam no confrontamento das experiências dos outros, formando, assim, uma rede de autoformação construída nas relações sociais e profissionais estabelecidas pelos docentes.

Durante a produção de fontes evidenciamos esses momentos na sala dos professores, nos corredores e no parque da instituição. Espaços esses que eram subvertidos com o intuito de potencializar as práticas pedagógicas e, também, avaliativas naquele contexto.

$\mathrm{Na}$ tabela 2 apresenta-se motivos levam os docentes a avaliar na educação infantil. São apresentados os itens com maior para menor recorrência.

Tabela 2 -

Motivos indicados pelos professores para realização da avaliação na educação infantil.

\begin{tabular}{l|c}
\hline Para cumprir os aspectos legais da profissão docente & 24 \\
\hline Para cumprir as normas institucionais & 24 \\
\hline Para mostrar a importância da educação infantil & 24 \\
\hline Para mostrar a importância do que ensino & 23 \\
\hline $\begin{array}{l}\text { Para legitimar meu trabalho frente à comunidade e } \\
\text { docentes }\end{array}$ & 20 \\
\hline $\begin{array}{l}\text { Para compreender aquilo que meu aluno aprendeu } \\
\text { dos conteúdos de ensino }\end{array}$ & 20 \\
\hline $\begin{array}{l}\text { Para captar aquilo que meu aluno faz com o que } \\
\text { aprendeu }\end{array}$ & 10 \\
\hline Para reorientar a minha prática docente & 9 \\
\hline Para ter subsídios para elaborar as fichas descritivas & 9 \\
\hline
\end{tabular}

Fonte: autores. 
Percebemos que as respostas com maior recorrência trazem como característica a articulação da atividade docente e seus reconhecimentos com os aspectos legais que preconizam a atuação na educação infantil, especialmente sobre a avaliação (Brasil, 2009). A necessidade de legitimar a atuação frente aos familiares também chama atenção, especialmente pelo imaginário social que atribui à educação infantil a natureza de espaço dissociado de saberes escolarizados (Lano, 2019).

Observamos que as opções com menor recorrência remetem a uma proposição avaliativa que busca compreender as aprendizagens das crianças e, também, a qualificação do próprio processo de ensino-aprendizagem, potencializando a açãoreflexão-ação das práticas avaliativas que permitam a tomada de decisão consciente sobre como encaminhar o percurso formativo (Santos, 2005).

No diário de campo, realizamos o registro da narrativa de P3, sobre as maneiras como ela mobiliza a avaliação a partir dos relatórios avaliativos descritivos ${ }^{14}$ :

"olha, lá no relatório eu coloco aquilo que fiz com as crianças, no caso com
'a criança', né, porque eles são individuais. Então, eu listo lá mais ou
menos assim: como a criança é em relação ao comportamento; como ele
se inseriu nas atividades que eu trabalhei; falo do que eu ensinei para ele;
falo se ele demorou aprender e do que precisa melhorar; isso no parcial,
né, no final eu coloco o consolidado. É importante escrever bem detalhado,
porque a pedagoga lê, os colegas leem e os pais leem também, é muita
responsabilidade." (Narrativa, P3, 2017)

A narrativa sinaliza as pistas (Ginzburg, 1989) das táticas (Certeau, 1994) utilizadas para a produção do relatório parcial e final de avaliação, sinalizando-o como um registro que dá visibilidade ao que foi trabalhado, mas que também fornece indícios sobre aquilo que precisa ser potencializado, permitindo ao docente reconstruir as suas ações no enriquecimento do percurso formativo compartilhado com as crianças.

Entretanto, a narrativa também apresenta que o objeto da avaliação é o comportamento. Ao atribuir centralidade a essa dimensão das aprendizagens, outros aspectos são secundarizados, como a compreensão das formas, das cores, da fauna e flora, do jogo de papéis nas brincadeiras e no patrimônio histórico cultural imaterial da humanidade.

Esses conhecimentos são mobilizados no cotidiano da instituição pesquisada mas que, no momento da configuração dos relatórios avaliativos, eles são inviabilizados em função da racionalidade avaliativa posta pela rede municipal de ensino.

Dessa maneira é importante compreender que a orientação institucional para o uso do relatório avaliativo põe os professores numa situação em que a evidência das aprendizagens, dos saberes de domínio e objetos (Charlot, 2000) se esvaziam nos registros oficiais, não divulgando aos familiares outras conquistas do processo de escolarização na educação infantil.

\footnotetext{
14 Os relatórios avaliativos descritivos constituem o mecanismo avaliativo oficializado pela rede municipal de ensino de Vila Velha/ES. Santos et al. (2017) destacam que essa ferramenta avaliativa é utilizada em $90 \%$ das redes municipais de ensino infantil no Espírito Santo.

Regae: Rev. Gest. Aval. Educ. Santa Maria v. 11 n. 20

\begin{tabular}{l|l}
20 & e68004, p. $1-18$
\end{tabular}

2022
} 
Esse entendimento nos permite chamar a atenção para a necessidade de promover maneiras de fazer (Certeau, 1994) para que professor e crianças analisem suas aprendizagens, observando aquilo que se faz com o que se aprende, reunindo pistas e indícios das aprendizagens (Santos, 2005; Vieira, 2018, Lano, 2019) com o intuito de potencializar as fichas avaliativas descritivas, caminhando em direção a um registro que visibilize as aprendizagens das crianças e, de certo modo, imprima sua marca no documento institucional com o intuito de visibilizar aquilo que se faz na educação infantil, assumindo uma prática investigativa (Esteban, 2001), que permite ao docente reunir aquilo que é produzido pelas crianças para, assim, tecer os fios do percurso formativo (Lano, 2019).

Desse modo, entendemos que a avaliação indiciaria (Santos, 2005; Vieira, 2018) contribui para o debate ao defender um processo avaliativo que desloque o olhar do docente para aquilo que se faz com o que se aprende e, assim, estabelecendo uma ação de reflexão-investigação.

\section{Das experiências compartilhadas à construção de práticas avaliativas}

Nessa categoria, analisamos quais as práticas avaliativas mobilizadas pelos docentes participantes da pesquisa no cotidiano de suas intervenções na Umei JSM. A Tabela 3, a seguir, apresenta os dados produzidos por meio do questionário semiestruturado. Destacamos que foi possível sinalizar mais de uma alternativa, tendo em vista a pluralidade como as práticas avaliativas se materializam na primeira etapa da educação básica.

Tabela 3 -

Registros avaliativos utilizados pelos professores da Umei JSM.

\begin{tabular}{l|c}
\hline $\begin{array}{l}\text { Caderno de registro do professor (registro subjetivo sobre } \\
\text { os aprendizados dos alunos durante as aulas) }\end{array}$ & 24 \\
\hline Ficha de avaliação oferecida pela Semed & 24 \\
\hline Registros fotográficos das aulas & 17 \\
\hline Registro em vídeos & 17 \\
\hline $\begin{array}{l}\text { Ficha descritiva individual (registro sistematizado com } \\
\text { alternativas de múltipla escolha sobre os aprendizados dos } \\
\text { alunos) }\end{array}$ & 7 \\
\hline Portfólio produzido pelo professor & 6 \\
\hline Desenhos de autoria dos alunos & 1 \\
\hline Criação individual: pintura, produção de brinquedos, etc. & 1 \\
\hline
\end{tabular}

Fonte: autores.

Antes da análise da tabela 3, é interessante perceber como o movimento autoformativo dos docentes ocorre a todo momento. Durante a devolução dos questionários, ouvimos deles narrativas como: "Olha, seu questionário me deu muitas ideias!"; "gostei das avaliações que tinham lá, vou tentar usar!"; "Você poderia me explicar melhor como funciona algumas daquelas avaliações? Fiquei interessada!” (Narrativas, professores, 2017). 
Essa ação evidencia como a complexidade do cotidiano (Certeau, 1994)', se apresenta e nas diferentes maneiras de consumo realizado pelos docentes para potencializar seu capital de práticas.

Nesse sentido, o caderno de registro do professor e a ficha avaliativa descritiva, assinalada por todos os professores, são usados como mecanismos que permitem comunicar o trabalho docente ou registro de práticas realizadas com as crianças ao longo do ano letivo. Durante a pesquisa, registramos em diário de campo diferentes narrativas que indiciavam como eram mobilizadas essas práticas no cotidiano escolar da educação infantil. Para P11, caderno do professor era um instrumento de registro das ações docentes no tempo:

"É ali que, nós, professoras, consultamos para saber o que escrever nas fichas, até porque ali estão registradas todas as atividades, projetos e outras coisas que fazemos com as crianças. Então é importante ter um caderno, até [P6], mesmo sendo de educação física tem um caderninho lá." (Narrativa, P11, 2017)

Para P6, o uso do caderno de registro como bloco de anotações estabelece conexão com o que foi ensinado e o que será ensinado nas próximas aulas:

"Lá, no meu caderninho, eu coloco algumas observações, aí eu vou comparando, vendo que foi melhor, quem precisa fazer mais, repetir mais, essas coisas. Eu deixo tudo anotado lá, às vezes não dá tempo, mas como agora eu tô mais tranquila no trabalho sempre que posso eu paro para anotar." (Narrativa, P6, 2017)

As pistas deixadas pelas narrativas sinalizam os usos (Certeau, 1994) do caderno do professor, ora se configurando como instrumento de apoio/complemento para a produção dos relatórios avaliativos descritos, ora sendo usado como fonte de registro das aprendizagens das crianças sobre um determinado conteúdo.

Assim, percebemos que as práticas partem de uma concepção de avaliação formativa reguladora. Vieira (2018) destaca que essa concepção é marcada por "um conjunto de ações de características informativa e reguladora, produzidas na interação dialógica de professores e alunos (p. 59)." Nesse sentido, as práticas avaliativas mapeadas pela tabela 3 destacam essa característica das ações, especialmente 0 caderno do professor.

Ressaltamos a necessidade de ampliar o sentido das práticas avaliativas, para além de uma concepção avaliação formativa reguladora, o qual considere somente as ações docentes. Dessa maneira, é preciso promover uma reflexão sobre o papel da criança, assumindo-a como sujeito de direitos, produtora de cultura e conhecimento em suas práticas (Vieira; Ferreira Neto; Santos, 2020).

Outro movimento interessante das práticas avaliativas sinalizadas pelos docentes da Umei JSM, por meio da tabela 3, são as práticas avaliativas nos usos de registros imagéticos com fotos e vídeos e portfólio produzido pelo professor como prática avaliativa. De acordo com Villas-Boas (2010), o uso do portfólio permite aos professores e crianças 
organizarem seus aprendizados, dispondo-se de materiais diversos que auxiliem na construção do saber. Nesse sentido, é interessante as narrativas de P7 e P11, registradas em diário de campo, que fazem fotos e vídeos cotidianamente das crianças:

"Eu faço muitos vídeos e muitas fotos, porque sempre precisa e eu aproveito sempre que trago meu notebook para escola para passar para as crianças as fotos deles, aí eu vou olhando as coisas e analisando, depois escrevo no meu caderno." (Narrativa, P7, 2017)

Já P11 utilizou os registros imagéticos de forma diferente de P7:

"Eu sempre gostei de registrar o que as crianças fazem, acho muito legal, aí eu sistematizo isso tudo num portfólio, faço uma capa bem colorida, e vou colocando foto, imprimo na escola mesmo, coloco também os artesanatos que dá, tem uns que não dá, aí no final do ano eu deixo exposto na minha sala, o pai que quiser pode pegar e ver. Eu gosto porque mostra pra eles que aqui não é só brincar, porque essa é a visão deles." (Narrativa, P11, 2017)

As narrativas evidenciam as diferentes maneiras de fazer dos docentes com o uso dos registros imagéticos, usados como subsídios para análise das aprendizagens e, também, para a construção de portfólios que evidenciem o trabalho pedagógico realizado durante o ano letivo, comunicando aos familiares o percurso formativo das crianças.

O diário de campo registrou um desses momentos em que P7 realizava esse movimento: "a professora fez uma rodinha com as crianças (sete) e está passando as fotos que bateu desde o início do ano, as crianças estão eufóricas e a todo momento destacam o que estavam fazendo naquele dia" (diário de campo, 2/5/2017). O registro de campo dá visibilidade às maneiras de fazer da docente com os registros imagéticos, que são as memórias do processo formativo externalizados pelas crianças que destacam, à sua maneira, o que estavam fazendo, comparavam-se com o colega e rememoravam outras ações ocorridas no dia, deixando pistas das aprendizagens.

É importante destacar que, ainda assim, houve a centralidade das ações da docente, cabendo a ela conduzir o processo de forma vertical, pouco explorando as narrativas das crianças e propiciando momento para que as crianças autoavaliassem seus avanços no conteúdo apropriado. A narrativa também evidencia a potencialidade do uso dos registros imagéticos na produção de registros avaliativos na interface com a memória. Pesquisas da área da educação física (Vieira, 2018; Santos et al., 2019) têm destacado o uso do registro imagético como prática avaliativa.

Salientamos a necessidade de se assumir uma concepção avaliativa que permita perceber, no processo de ensino, as pistas deixadas pelas crianças nas análises de suas aprendizagens. Dessa maneira, pode-se não só reorganizar as práticas a partir da compreensão das aprendizagens, mas também projetar práticas que permitam às crianças utilizarem e compreenderem as relações realizadas com suas aprendizagens (Lano, 2019). 
Nesse sentido, é importante relembrar que a avaliação indiciária se situa na fronteira do saber e do não saber, assim a própria elaboração da ficha avaliativa descritiva, ao ser atravessada por essa concepção, poderia potencializar a sua escrita no sentido de dar visibilidade aos ainda não saberes das crianças que se encontram em elaboração na parceria entre os pares, professores e familiares.

Assim como outras professoras da instituição, $\mathrm{P} 11$, em sua narrativa, deu ênfase à outra possibilidade de utilização do portfólio, que se configura como um registro daquilo que foi realizado ou confeccionado durante o ano letivo. O que chama a atenção é o seu uso posterior, uma vez que a narrativa sinaliza que as crianças não participam de sua construção, tampouco visualizam o material antes de ser exposto aos familiares.

Sobre o uso do portfólio como prática avaliativa na educação infantil, assumindo-a como protagonista desse processo, Tonello (2015) destaca que a seleção dos materiais que compõem o portfólio é uma ação que objetiva dar ênfase à memória e identidade do processo educativo produzido com as crianças.

Os movimentos formativos realizados pelos docentes impactam na própria compreensão das práticas avaliativas e seu sentido. Se a avaliação na Umei JSM é formativa e democrática, pois compartilha com a comunidade escolar os avanços da criança (Brasil, 2017), e está direcionada para incluir todos nesse processo, o uso do portfólio para produzir uma memória do percurso formativo desloca a racionalidade avaliativa para o campo do ensino, uma vez que ele tem dado visibilidade ao que foi construído ao longo do ano, mas esvazia a participação das crianças em seu processo de construção.

\section{O reconhecimento das práticas pedagógicas como avaliativas}

No período em que estivemos na Umei JSM, percebemos um movimento de produção de práticas pedagógicas que emergiam da identificação da identidade das crianças (Sarmento, 2011), de suas maneiras de produção cultural e das formas de interação com os outros a partir da ludicidade.

Essas ações se materializavam em produções coletivas entre professores e crianças, geralmente mediada pelo uso do desenho. A imagem 1 evidencia esse movimento. 
Imagem 1 -

Desenhos sobre as brincadeiras realizadas no parquinho.

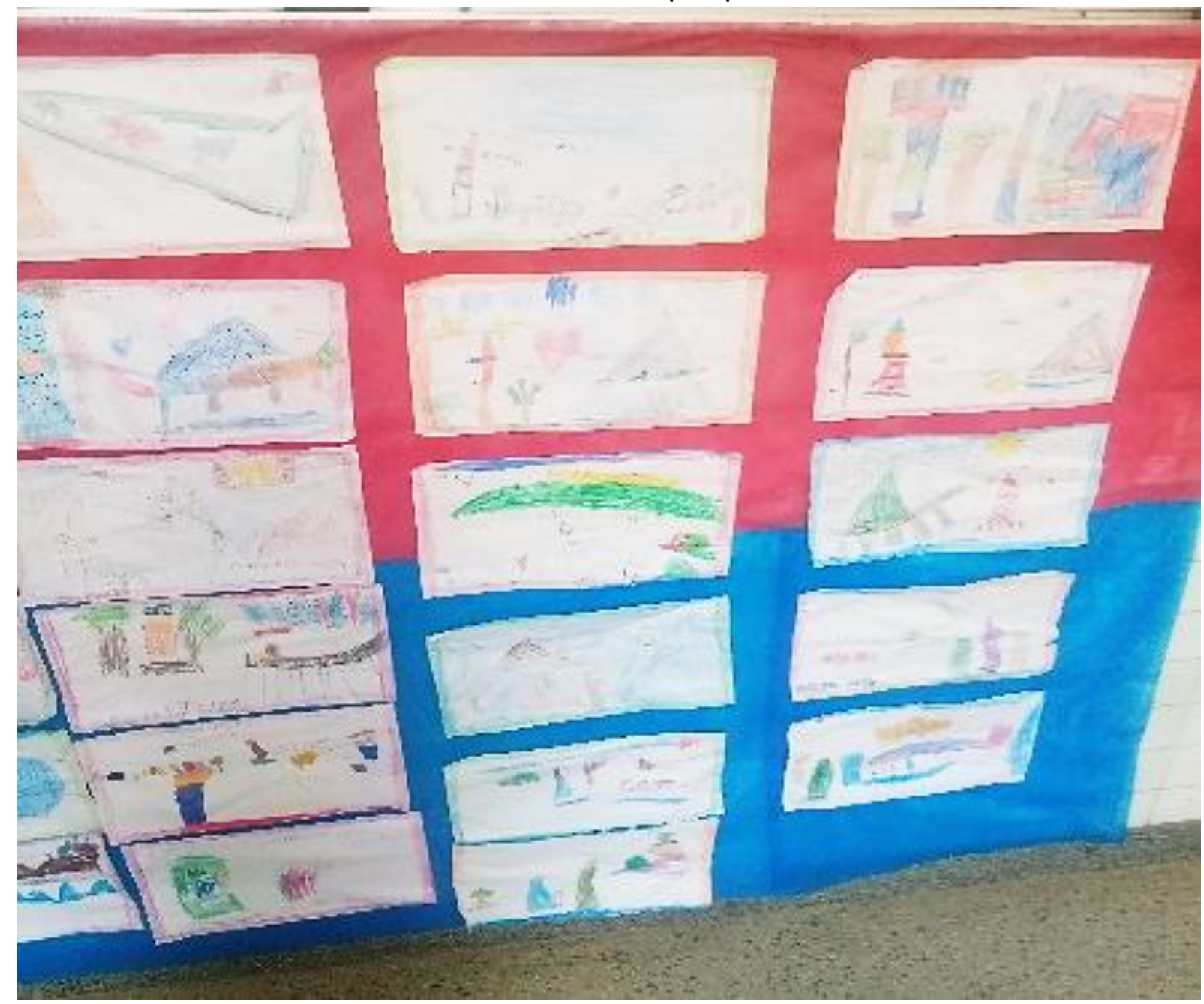

Fonte: autores.

Pergunta: Por que você pediu para as crianças fazerem os desenhos? 0 que significa?

P14: "Então, eu os levei no parquinho e fizemos várias brincadeiras, levei os brinquedinhos, quem queria podia brincar com seus brinquedinhos, mas quase nenhum quis. Depois, sentamos lá mesmo, fizemos uma rodinha eu a [estagiária] e a [cuidadora] e contamos uma historinha pra eles, historinha da gotinha, vamos dançar ela no final do mês. Aí, chegando na sala pedi eles para desenharem um pouco, faltava 30 minutos para a hora da saída, disse que podiam desenhar o parquinho, aí saiu isso, achei bonito, peguei eles e fiz esse painel para os pais verem." (Narrativa P14, 2017)

A narrativa mostra uma intencionalidade ilustrativa do desenho, colocando-o como suporte das ações pedagógicas desenvolvidas com as crianças. Contudo, a professora não confere sentidos a esse fazer como uma ação avaliativa investigativa (Esteban, 2001), uma vez que é possível analisar qualitativamente os desenhos e no diálogo com as crianças buscar os sentidos atribuídos em suas produções, fazendo com que elas revelem suas aprendizagens, suas conquistas e dúvidas presentes na prática pedagógica. 
Santos et al. (2019) destacam que o uso do desenho como prática avaliativa formativa, permite as crianças produzirem um registro daquilo que foi compreendido no processo de ensino e aprendizagem. Ao analisar esse registro, as crianças revelam não só aquilo que está representado e que marcou seu processo de aprendizagem, mas também as relações com o saber (Charlot, 2000) compartilhadas entre pares.

Para além disso, é importante destacar que o desenho se encontra na cultura escolar, especialmente na educação infantil (Lano, 2019; Tonello, 2015), como meio para o processo de aprendizagem, mas que pouco é explorada como a intencionalidade de compreensão daquilo que foi aprendido pelas crianças no cotidiano escolar.

Nesse caso, é preciso considerar aquilo que Benjamin (1994) nos ensina. O autor destaca que lemos o mundo por meio das imagens e que nossa memória é um catálogo, assim, o que é narrado pela criança por meio do registro imagético são as imagens que constituem a memória do aprendizado, da sua produção de sentido peculiar e particular, em uma relação experiencial com o saber.

Para além disso, o uso do desenho como instrumento (Vygostky, 1998), que amplia os sentidos sobre um determinado signo, permite às crianças impulsionarem seu desenvolvimento, especialmente no momento em que ela precisa do outro para concluir a atividade e, assim, se aproximar do seu aprendizado.

A partir do entendimento que destaca a atribuição de sentidos e o trabalho colaborativo entre as crianças no contexto da escolarização, destacamos que a educação infantil é um espaço (Certeau, 1994) produzido na interação entre aqueles que compõem o cotidiano escolar e, nesse sentido, as interações com os jogos, brinquedos e brincadeiras utilizadas por todos os docentes que compõem esse lugar constitui a principal fonte de construção de saberes das crianças, relacionando aquilo que faz parte do saber-objeto por meio dos saberes de domínio e relacional (Charlot, 2000).

Assim, na articulação do desenho com a avaliação indiciária, Santos et al. (2015; 2019) destacaram que o registro imagético permite às crianças narrarem suas experiências corporais, atribuindo juízo de valor sobre aquilo que foi relevante naqueles momentos do percurso formativo, inclusive dando forma ao que foi apropriado.

No processo de produção de fontes, registramos em diferentes momentos, o uso do desenho pelos docentes da Umei JSM. Ao questionar P18, que possuía o menor tempo de experiência na educação infantil sobre o uso do desenho, ela destacou que "eu reconheço que ali [desenho] tem um potencial avaliativo, mas por vezes a quantidade de trabalho me atrapalha, sabe, para olhar com calma, ouvir com calma as crianças" (Narrativa, P18, 2017).

A narrativa de P18 é algo compartilhado por outros docentes: em nosso diário de campo registramos 12 ocorrências de narrativas que destacam a rotina de trabalho como atravessamento da prática docente, impactando em diferentes ações docentes, especialmente na avaliativa.

Isto posto, assim como Alavarse, Chappaz e Freitas (2021), chamamos atenção para os cursos de formação de professores, em especial para a educação infantil, sobre a necessidade do enriquecimento do debate sobre avaliação para aprendizagem, no intuito de tornar o processo algo intrínseco ao fazer diário desses profissionais, que na medida 
em que se planeja e projeta as ações educacional se investigue como elas são apropriadas pelas crianças e como estabelecer uma relação colaborativa para potencializar o percurso formativo.

Portanto, destacamos que é necessário, no cotidiano escolar da educação infantil, ampliar a compreensão daquilo que se faz nesse contexto com o intuito de refletir sobre os processos de ensino-aprendizagem, compreendendo o próprio lugar do desenho como ação pedagógica e avaliativa. Especificamente sobre o desenho, salientamos que ações, como a da imagem 1, foram produzidas naquele ano letivo por 17 dos 24 docentes da instituição.

No cruzamento das fontes, a tabela 3 destaca que somente um docente percebeu o desenho como avaliação para aprendizagem, mas no dia-a-dia do trabalho docente o mesmo foi usado como prática lúdica. É nesse movimento que defendemos aquilo que Lano (2019) e Santos et al. (2019) destacam sobre o uso do desenho como fonte de subsídios para a tomada de decisão na elaboração ou reestruturação dos processos pedagógicos na educação básica, especialmente na educação infantil.

Nesse caminho, considerar a criança como produtora de cultura e protagonista de sua formação permite ao docente investigar (Esteban, 2001) aquilo que é produzido, ampliando a sua base interpretativa, procurando as pistas e sinais do percurso formativo, caminhando para um processo avaliativo que olhe as aprendizagens construídas cotidianamente por meio de processos sutis.

\section{Considerações finais}

Por meio da pesquisa objetivou-se compreender quais os sentidos atribuídos pelos docentes de uma instituição de educação infantil sobre a avaliação para aprendizagem, identificando aquilo que os mobiliza e as práticas avaliativas utilizadas no cotidiano escolar.

Nesse caminho, identificamos que a formação inicial não se constituiu como um espaço destinado ao debate sobre as práticas avaliativas na educação infantil e que, em função disso, os docentes se apropriam de diferentes espaços de formação que lhes são ofertados, como os cursos disponibilizados pela administração pública e as redes autoformativas constituídas no cotidiano escolar. Percebemos que, nesse movimento de apropriação de saber na relação com o outro (Charlot, 2000), os docentes vão produzindo diferentes formas de mobilizar as práticas avaliativas no cotidiano escolar.

Embora as fichas avaliativas descritivas sejam os instrumentos utilizados, especialmente pela sua obrigatoriedade, os docentes constroem outras práticas pedagógicas com as crianças no cotidiano escolar que Ihes permitem investigarem as aprendizagens. Entretanto, por vezes, eles não se constituem como fontes que subsidiem a produção dos relatórios, centralizando suas análises na atuação docente em detrimento dos avanços das crianças no processo de escolarização.

De certo modo identificamos, ao analisar nossos dados produzidos, que os docentes se aproximam de uma concepção avaliativa formativa reguladora (Vieira, 2018) que centraliza suas ações no fazer docente. Dessa forma, os registros avaliativos se configuram como ações informativas que buscam regular o processo formativo de 
maneira linear, secundarizando, nos registros avaliativos, os saberes objeto e de domínio (Charlot, 2000). Isso não significa que eles não são privilegiados no fazer cotidiano dos docentes, mas que estão em segundo plano ao se produzir práticas avaliativas naquele contexto.

Nesse sentido, chamamos atenção para a possibilidade de usos da avaliação indiciária (Santos, 2005; Vieira, 2018) como concepção avaliativa na educação infantil, pois ela pode permitir ao professor produzir práticas investigativas que dialogam com a especificidade das crianças, potencializando a avaliação para a aprendizagem que ocorre nessa etapa da educação infantil, enriquecendo a própria escrita dos relatórios avaliativos descritos.

\section{Referências}

ALAVARSE, Ocimar Munhoz; CHAPPAZ, Raíssa de Oliveira; FREITAS, Pâmela Feliz. Avaliações da aprendizagem externas em larga escala e gestores escolares: características, controvérsias e alternativas. Cadernos de Pesquisa, São Luís, v. 28, n. 1, 2021, p.224-250.

BARCELOS, Marciel; SANTOS, Wagner; FERREIRA NETO, Amarílio. Aprender na educação física: diálogos com as crianças e a professora. Journal of Physical Education, Maringá, v. 28, 2017, p. 1-16.

BARCELOS, Marciel; SANTOS, Wagner; FERREIRA NETO, Amarílio. Crianças, infância e escolarização: tessituras na transição da educação infantil para o ensino fundamental de nove anos. Motrivivência, Florianópolis, v. 27, 2015, p. 84-101.

BENJAMIN, Walter. Obras escolhidas: magia e técnica. São Paulo: Brasiliense, 1994.

CERTEAU, Michel de. A invenção do cotidiano: artes de fazer. Petrópolis: Vozes, 1994.

COSTA, Oséias Silva. Avaliação formativa na educação: um passo para o sucesso. Regae: Rev. Gest. Ava. Educ., Santa Maria, v. 6, n. 11, 2017, p. 137-141.

CHARLOT, Bernard. Da relação com o saber: elementos para uma teoria. Porto Alegre: Artes Médicas, 2000.

ESTEBAN, Maria Teresa. O que sabe quem erra? Reflexões sobre a avaliação e fracasso escolar. Rio de Janeiro: DP\&A, 2001.

FUZII, Fábio Tomio. Formação de professores de educação física e avaliação: investigando a reestruturação curricular dos cursos de licenciatura. Rio Claro: Unesp, 2010. 197f. Dissertação (Mestrado em Pedagogia da Motricidade Humana). Programa de Pós-Graduação em Ciências da Motricidade, Universidade Estadual Paulista.

GINZBURG, Carlo. Mitos, emblemas, sinais: morfologia e história. São Paulo: Companhia das Letras, 1989.

GLAP, Graciele; BRANDELISE, Mary Ângela Teixeira; ROSSO, Ademir José. Análise da produção acadêmica sobre a avaliação na/da educação infantil do período 2000-2012. Praxis Educativa, Ponta Grossa, v. 9, n. 1, 2014, p. 43-67.

GOC-KARP, Grace; WOODS, Marianne. Preservice teacher's perceptions about assessment and it's implementation. Journal of Teaching in Physical Education, Champaign, v. 27, n. 3, 2008, p. 327-346. 
HARLEN, W; JAMES, M. Assessment and learning: differences and relationships between formative and summative assessment. Assessment in education: principles, police and practice, Londres, v. 4, n. 3, 1997, p. 365-379.

HOFFMANN, Jussara. Dossiês, portfólios, relatórios de avaliação. In: HOFFMANN, Jussara. Avaliar para promover: as setas do caminho. Porto Alegre: Mediação, 2004, p. 200-207.

LANO, Marciel Barcelos. Praticas cotidianas da educação física na transição da educação infantil ao ensino fundamental. Vitória: Ufes, 2015. 121f. Dissertação (Mestrado em Educação Física). Programa de Pós-Graduação em Educação Física, Universidade Federal do Espírito Santo.

LÓPEZ-PASTOR, Victor et al. Alternative assessment in physical education: a review of international literature. Sport, Education and Society, Quorn, v. 18, n. 1, 2013, p. 57-76.

MOTA, Diego; MAMADE-NEVES, Maria Apparecida Campos. Percepções e representações sociais de professores acerca de avaliação da aprendizagem: um estudo das produções em teses e dissertações (2009-2019). Regae: Rev. Gest. Ava. Educ., Santa Maria, v. 10, n. 19, 2021. p. 1-21.

SANTOS, Wagner et al. Avaliação em educação física escolar: trajetória da produção acadêmica em periódicos (1932-2014). Movimento, Porto Alegre, v. 24, n. 1, 2018, p. 922.

SANTOS, Wagner et al. Avaliação na educação física escolar: construindo possibilidades para a atuação profissional. Educação em Revista, Belo Horizonte, v. 30, n. 4, 2014, p. 153-179.

SANTOS, Wagner et al. Avaliação na educação física escolar: reconhecendo a especificidade de um componente curricular. Movimento, Porto Alegre, v. 21, n. 1, 2015, p. 1-15.

SANTOS, Wagner et al. Educação física na educação infantil: um olhar sobre o panorama do Estado do Espírito Santo. In: SCHNEIDER, Omar; GAMA, Jean Carlo Freitas (org.). Educação física e seus caminhos: programa de educação tutorial. Vitória: Virtual Livros, 2017, v. 1, p. 19-46.

SANTOS, Wagner. Currículo e avaliação na educação física: do mergulho à intervenção. Vitória: Proteoria, 2005.

SANTOS, Wagner; MAXIMIANO, Francine Lima. Avaliação na Educação Física escolar: singularidades e diferenciações de um componente curricular. Revista Brasileira de Ciências do Esporte, Brasília, v. 35, 2013, p. 883-896.

SARMENTO, Manuel Jacinto. A reinvenção do ofício de criança e de aluno. Atos de Pesquisa em Educação, Blumenau, v. 6, n. 3, 2011, p. 581-602.

SARMENTO, Manuel Jacinto. O estudo de caso etnográfico em educação. In: ZAGO, Nadir; CARVALHO, Marília Pinto de; VILELA, Rita Amélia Teixeira (orgs.). Itinerários de pesquisa: perspectivas qualitativas em sociologia da educação. Rio de Janeiro: DP\&A, 2003, p. 137-179.

SILVA, Alcir Horácio. A organização do trabalho pedagógico e a avaliação da aprendizagem na educação física no Colégio de Aplicação da UFG. Salvador: UFBA, 2010. 210f. Tese (Doutorado em Educação). Programa de Pós-Graduação em Educação, Universidade Federal da Bahia. 
TONELLO, Denise Maria Milan. Portfólios na educação infantil: um projeto de intervenção fundamentado na ação formativa. São Paulo: PUCSP, 2015. 131f. Dissertação (Mestrado em Educação). Programa de Pós-Graduação em Educação, Pontifícia Universidade Católica de São Paulo.

VIEIRA, Aline Oliveira. Educação Física e a Pedagogia da Infância: leituras das práticas avaliativas por narrativas e imagens. Vitória: Ufes, 2018. 320f. Tese (Doutorado em Educação Física). Programa de Pós-Graduação em Educação Física, Universidade Federal do Espírito Santo.

VIEIRA, Aline Oliveira; FERREIRA NETO, Amarílio; SANTOS, Wagner. Práticas avaliativas indiciárias e os sentidos atribuídos ao aprender na educação física em nove anos de escolarização. Revista Humanidades \& Inovação, Palmas, v. 7, n. 10, 2020, p. 200-207.

VYGOTSKY, Lev Semionovitch. Pensamento e linguagem. Rio de Janeiro: Martins Fontes, 1998.

Marciel Barcelos é professor no Programa de Pós-Graduação em Educação na Universidade Federal do Tocantins.

Orcid: https://orcid.org/0000-0003-1181-8724.

Endereço: Arne 64, Alameda 11, Lote 2, apto 103, bloco A - 77006-652 - Palmas TO - Brasil.

E-mail: marcielbarcelos@gmail.com.

Aline Oliveira Vieira é professora na Prefeitura Municipal de Serra/ES.

Orcid: https://orcid.org/0000-0002-4059-6780.

Endereço: Res. Serra Sede - R. José Francisco - Colina da Serra - 29176-070 - Serra

- ES - Brasil.

E-mail: ninamanguinhos@gmail.com.

Wagner dos Santos é professor no Programa de Pós-Graduação em Educação na Universidade Federal do Espírito Santo.

Orcid: https://orcid.org/0000-0002-9216-7291.

Endereço: Avenida Fernando Ferrari, 514 - 29075-910 - Vitória - ES - Brasil.

E-mail: wagnercefd@gmail.com.

Critérios de autoria: os autores, coletivamente, realizaram a concepção, criação e consolidação do artigo.

Recebido em 6 de outubro de 2021.

Aceito em 17 de dezembro de 2021.

(c) (i) (3) $\odot$

v. 11

ก. 20

e68004, p. $1-18$

2022 